\title{
Depression status in patient with adolescent idiopathic scoliosis: A comparative study
}

\author{
T Kuru $^{1 *}$, H Yilmaz ${ }^{2}$, E Dereli ${ }^{3}$, F Hozatlioglu², B Çelik ${ }^{2}$ I Çolak ${ }^{4}$ \\ From 9th International Conference on Conservative Management of Spinal Deformities - SOSORT 2012 \\ Annual Meeting \\ Milan, Italy. 10-12 May 2012
}

\section{Background}

The adolescent years are one of the most stressful times in a person's life and if they have idiopathic scoliosis, spinal deformity and brace treatment can cause psychological effects.

\section{Aim}

Our aim was to investigate depressive symptoms in children and adolescents with idiopathic scoliosis and their association with demographic and wearing brace variables.

\section{Methods}

Study included 47 (7 male, 40 female) participants, 23 were using brace (mean age: $13.34 \pm 1.61$ ) and 24 were doing 3D- Schroth method exercises (mean age: $13.66 \pm 1.76)$ for treatment. In the brace group, mean Cobb angle was 38.30 \pm 10.70 (range:20-60), mean ATR was $12.60 \pm 5.41$ (range:3-25), in the exercise group mean Cobb angle was $32.16 \pm 11.62$ (range:15-60), mean ATR was $8.45 \pm 4.04$ (range:3-18). Both of the groups were receiving treatment for 6 months at least. Depressive symptoms in youth were assessed with the Children's Depression Inventory (CDI), a self-report questionnaire consisting of 27 items. The CDI has wide use across chronic health conditions. A score of 13 is indicative of elevated depressive symptoms.

\section{Results}

In the brace group 5 of $23(21.5 \%)$ and in the exercise group 4 of $24(16.8 \%)$ patients were scored on the CDI at or above the clinical cutoff $(\mathrm{p}=0.554)$. There were no significant correlation between the Cobb angle, rotation angle, BMI, age and CDI scores $(\mathrm{p}=0.214, \mathrm{p}=0.034$, $\mathrm{p}=0.335, \mathrm{p}=0.027$ ).

\section{Conclusion}

Findings indicated that nearly one in five youth with adolescent idiopathic scoliosis met the clinical cutoff for depression by their own report. Study results showed that there are no significant differences between brace and exercise therapies on depression status. Multidisciplinary scoliosis teams are in an ideal position to offer early identification and optimum treatment for adolescent idiopathic scoliosis.

\section{Author details}

${ }^{1}$ Istanbul University, Faculty of Health Science, Department of Physiotherapy and Rehabilitation, Istanbul, Turkey. ${ }^{2}$ Haliç University, Halic University, School of Health Sciences, Department of Physiotherapy and Rehabilitation, Istanbul, Turkey. ${ }^{3}$ Istanbul Bilgi University, School of Health Science, Department of Physiotherapy and Rehabilitation, Istanbul, Turkey. ${ }^{4}$ Dr.Lütfi Kırdar Kartal Education and Research Hospital, Istanbul, Turkey.

\section{Published: 3 June 2013}

\section{References}

1. M K: Children's Depression Inventory. Los Angeles: Western Psychological Services; 1992.

2. Noonan KJ, Dolan LA, Jacobson WC, Weinstein SL: Long-term psychosocial characteristics of patients treated for idiopathic scoliosis. J Pediatr Orthop 1997, 17(6):712-717.

3. MacLean WE Jr., Green NE, Pierre CB, Ray DC: Stress and coping with scoliosis: psychological effects on adolescents and their families. J Pediatr Orthop 1989, 9(3):257-261.

doi:10.1186/1748-7161-8-S1-P7

Cite this article as: Kuru et al:: Depression status in patient with adolescent idiopathic scoliosis: A comparative study. Scoliosis 2013 8(Suppl 1):P7 